\title{
Two Distinct Theories of Production: Lean and Toyota Management System
}

\author{
Rikke V. Matthiesen \\ Aalborg University, Center for Industrial Production, \\ Fibigerstræde 16, 9220 Aalborg, Denmark \\ rikkevmaproduction.aau.dk
}

\begin{abstract}
The paper analyses differences between "lean" and its sister concept "Toyota management system (TMS)" by drawing out deep-rooted theories of production within these two streams of literature. The paper argues that such deep-rooted beliefs should be the first target for organizational transformation as these beliefs provide an important contextual layer for any attempts to transfer organizational practices from one organization to another. Examples of implications in relation to translation are sketched out.
\end{abstract}

Keywords: Lean, TPS/TMS, translation theory, production philosophy.

\section{Introduction}

The literature on failed transition efforts inspired by Japanese concepts is abundant. Some writers have pointed to aspects of organizational environment, managerial behavior and beliefs, or leadership qualities in order to explain the performance and dynamic capabilities of Toyota. It appears from other analyses however, that lean evades precise definition and communication. Hines et al [1] find that the literature on lean is continuously expanding its focus in terms of scope of application in the supply chain. Liker et al [2] suggest that any core practices of Japanese management systems that is attempted transferred, will need to be integrated with systems and practices in a range of contextual layers in highly context specific ways. In line with this proposition, the expansion of the lean concept [1] may be interpreted as a matter of addressing ever more aspects of Toyota's managerial system in the lean literature.

Uncertainty regarding complicated interactions between various system aspects [2] has resulted in attempts to engage in perfect/complete practice adoption. The underlying assumption is that relevant contextual ties affecting core practices can be addressed if a wide set of peripheral practices are also implemented. This approach is supported by some research, see e.g. [3]. However, there are several risks involved in this approach, and conceptually, it may be neither feasible nor desirable. Several sources acknowledge that Toyota applies an integrated manufacturing and management system. In a sketch of a holistic model of such system, also product features may be included [4]. This illustrates the span of TPS. At the same time it has been suggested that TPS may establish a carefully designed configuration of job 
characteristics that lead to worker motivation and positive employee outcomes required to operate other aspects of TPS [5]. In combination, these sources emphasize that TPS is not a discrete set of practices, a system perspective may be more appropriate. However, how to codify and transfer a system from one context to another?

\section{Theoretical Background}

The current approach found in lean literature tends to isolate sets of practices and present these as representative of the entire system. This approach falls in the category of analytical reduction; assuming the whole can be studied by studying the characteristics of the pieces. Such approach may be helpful in understanding how different practices work. But it is not helpful as the basis for organizational transformation. Any practice may in its implementation and use be distorted to reproduce former managerial assumptions [6] and they may be selected and/or enacted so that unfamiliar ideas are not adopted [7]. So while TPS may be conceptualized as a system of practices, organizational transformation on the other hand cannot be conceptualized as practice adoption. Selective practice adoption may not lead to the context specific configurations required to obtain the desired systems effects.

\subsection{Concept Driven Change and Organizational Transformation}

Gustavsen et al [8] describe the Japanese inspired change efforts as "concept driven" and characterize this type of change as widely communication driven. With communication as the change driver, translation theories show their relevance. Within translation theory, Røvik [9] describes the process of adopting managerial concepts as that of interpreting practices. In this process, practices may undergo considerable transformation either purposefully or unintended as referred to above. Therefore, as argued above, organizational transformation inspired by Toyota should not be seen as a matter of decontextualizing and transferring practices from one system to another. Instead, there is a need for re-conceptualizing content and context.

\subsection{Design Principles as a Contextual Layer}

Traditionally, contextual layers have been thought of as related to physical and institutional scope such as e.g. wider organizational practices [2], laws and regulations, or cultural traits [9]. Spear however, suggests that TPS practices should be considered artefacts of a certain set of system design principles applied within Toyota [10]. Within production and operations management, such system design principles could be seen as a more subject-relevant contextual layer influencing how production and operations practices are identified, captured, transferred, and managed across organizations. This implies that organizational transformation inspired by Toyota should be viewed as a matter of transferring concepts and design principles in use from one organization to another. At present, the literature on TPS production techniques (lean literature) function as one of two contexts for our understanding of Toyota. 
Another context is the literature on organizational aspects within TMS and Japanese management systems. Unfortunately these two streams are poorly integrated. The aim of this paper is to identify the sets of deep-rooted beliefs that these streams of literature explicitly or implicitly represent in order to facilitate future integration.

\subsection{Theories of Production as the Underlying Context}

The objectives of the paper call for a framework that provides sufficient level of abstraction to handle the diverse perspectives or traditions. The paper proposes that such framework may be found in the work by Koskela [11] who proposes to address production theories at three levels:

1. A conceptualization of production.

2. Universal laws and causal relations that would apply under the specific conceptualization of production.

3. Design, control and improvement principles that follow from these causal relations.

Using this theoretical framework, Koskela identifies the deep-rooted beliefs held within three different production theories, among these the production theory that prevailed in the West before the strong orientation towards Japanese manufacturing as well as lean. This is detailed below. Using this framework, design principles as identified by Spear [10] are positioned as stemming from more fundamental beliefs about production. In order to identify the overarching conceptualization of production within TMS that matches these system design principles, a review of a narrow set of writings on TMS is conducted. First the application of the framework on lean literature will be detailed.

\section{Theories of Lean Production}

Koskela [11] describes the production theory that previously prevailed in the West as a transformation perspective. In this perspective, production is seen as a set of resource consuming transformation activities (cost centers) that should be optimized in terms of input/output. It is assumed within this perspective, that the entire transformation process can be subdivided into sub-processes which are also transformation processes and that the resources put into the set of individual transformation activities determine the overall cost of an item. I.e. sub-processes are considered to be independent.

Koskela characterizes Japanese manufacturing as embedding a flow perspective. In this perspective, time, not only as a dimension for coordination, but also as a valuable resource, is introduced into production theory. The notion of time as a resource allows us to see production as a coordinated flow of materials (level 1 in a production theory). This is a conceptualization of production distinct from the former Western conceptualization. It establishes queuing analysis as the set of governing laws (level 2 in a production theory). These laws establish the link between variability and deteriorated performance in terms of WIP levels, lead times, variable process times, and less than optimal capacity utilization [12]. Hopp \& Spearman [12] suggest that 
lean production is aimed at minimizing the cost of buffering variability which can be achieved by a combination of intelligent buffer switching, use of flexible resources, and variability reduction (level 3 in a production theory). Understanding these fundamental design, control and improvement principles, a wide range of lean tools and techniques can be argued for theoretically instead of dogmatically.

\section{Theories of Production within TMS}

Koskela points out that he presents " $a$ 'pure' production theory [which] focuses just on the act of production. It does not deal with such issues as what is the nature of machines or humans as workers or how production should be divided among individuals (the problem of organizing)." (p28)[11]. However, with a "pure production theory" as a starting point, the role of the wider organization including HR may easily be reduced to that of providing conditions favorable to smooth production. This includes the emphasis on HRM practices for ensuring employee motivation and worker flexibility found in previous lean literature. Broader issues of organizing are precisely the concern of literature on TMS. However, as indicated above, a theory of production within TMS is missing. In the following, work by de Treville and by Spear is reviewed in order to establish requirements for a theory of production within TMS.

In her $\mathrm{PhD}$ thesis [13], de Treville investigated JIT implementations and developed a typology of JIT systems as combinations of JIT flow control and either of the two elements: Flexible resources for improved line balance, and/or learning through disruptions occurring at less than optimal buffer levels. She argued that the application of JIT flow control alone would not lead to the ideal rate of learning (process improvement). She also argued that disruption as means for learning should primarily be applied in situations where production inefficiencies could not be found analytically. This implies situations in which queuing analyses may explain relationships between variability and deteriorated throughput rates but will not suffice to identify leverage points in the system. In her analysis of a set of JIT implementation cases, she found that learning through forced disruptions needs to be carefully managed. Otherwise this practice will lead to unnecessary productivity losses which will stress organizations that, in line with the transformation perspective, have been used to keeping all resources busy at all times and fail to see these disruptions as valuable sources of information. In [5] she furthermore position respect for people, the establishment of good job characteristics and motivation as an important subsystem of TPS in line with lean material flow. In regards to the establishment of a theory of production within TMS the key take aways from this work may be suggested to be:

- Proper operation of JIT requires a willingness to invest in learning by exchanging short term productivity for information in order to obtain long term productivity gains. "All other aspects of JIT can be supported using traditional arguments" (p1-16)[13].

- Idle workers may be seen as a resource rather than an issue. Cross training for improved line balance may also be considered a type of learning that can arise 
from buffer removal. [13]. I.e. there are multiple ways of building up organizational resources associated with JIT practices.

- Using disruptions for learning requires careful management of improvement activities and buffers to avoid unnecessary productivity losses and organizational stress [13].

- JIT is constituted not of one system per plant or material flow but of one system between each two production groups. "A separate decision as to the "best" type of JIT must be made for every intermediate buffer." (p4-25)[13]. I.e. the application of JIT systems require significant amounts of context specific design choices.

- Employee motivation and respect are important subsystems of TPS. Worker motivation in a lean environment using job standards is especially dependent on the experience of skill variety and responsible autonomy [5]. I.e. application of lean production practices requires careful application of HR practices.

In the following, work by Spear [14, 10, 15] is reviewed. Spear \& Bowen [14] describe Toyota as a community of scientists conducting scientific experiments. Spear [10] argues that constant application of rules-in-use (specify, build in tests and improve) to system design constitute meta routines that create "highly situated learning that is both broadly distributed" (p2) and where "learning ... occurs through frequent practice that allows for repeated failure" (p23) [10]. Spear [15] state that "The point of process improvement is to improve the participants' process-improvement capabilities by coaching them as they try to improve the process." (ibid p218). Toyota furthermore takes significant care to extract and disseminate learning from this process [15]. Engagement in Toyota style process improvement is thus a means for improving individual processes as well as a means for accumulating organizational resources in terms of individual skills for process improvement and in terms of widely distributed deep process and design knowledge. With these by-products of process improvement, Spear reverses the roles of organization and production: "The factory was not only a place to produce physical products, it was also a place to learn how to produce those products and [...] keep learning how to produce those products." (p15)[15]. In regards to the establishment of a theory of production within TMS, the following should be emphasized:

- System design rules that work to reduce variability combined with strict specification allows for detection of and learning about process inefficiencies. [14]

- Production may be thought of as repetitive activities that through permutations provide learning opportunities for the organization. [15]

- Learning opportunities should be exploited to create better process designs and build resources in terms of process improvement skills in the individual, and in terms of accumulated process knowledge. [15]

- The organization not only operates production but also continuously redesigns production. Highly situated learning [10] implies highly situated design which requires design knowledge and skills in even the smallest units: The work teams, team leaders etc. 


\section{Synthesis}

Based on the above, three different theories of production can be sketched. A traditional Western transformation perspective offered by Koskela [11]. A lean production philosophy oriented towards flow offered by Koskela [11] and Hopp \& Spearman [12] in line with industrial engineering reasoning. And a theory of production within TMS, which accommodates for a preference for learning and similar resource based concerns:

1. Production may be conceptualized as a stream of repetitive activities linked through material and information flows, which creates an arena for the organization's continued learning and design efforts.

2. The amount of information that can be extracted from the engagement in production activities depends on the extent to which activities are prespecified, production groups are linked in dedicated flows, relevant buffers are kept small enough for production inefficiencies to trigger disruptions and motivate improvement, as well as employee skills for designing and analyzing production.

3. Design, control and improvement principles should comply with the short term goal of optimizing individual processes in line with the lean production philosophy and with the long term goal of maximizing organizational capabilities for process design.

\section{Implications}

These three different theories of production may be regarded as different contexts for the design and management of various subsystems of production. This is exemplified in the following with a focus on HRM as a subsystem.

A transformation perspective may foster a view of labor as cost similar to other resources consumed in the transformation activities. In the extreme, the worker may be thought of as an acquired, temporary resource intended for certain production tasks. Training can extend the skills of the worker and may be a necessary investment required to make full use of the resource. However, there will be a balance between cost of training and process requirements. It follows that training is best invested in skills required for the operation of a limited number of production activities.

In a lean production philosophy, training may be more widely engaged in as multi skilling is a means for balancing production lines. The requirements for such multi skilling changes as the line is improved towards reduced variability. If the lean setup is established through the use of "lean tools", additional training may be required to equip the worker to operate these curious tools (kanbans, SOPs etc). The corresponding system specific knowledge in traditional operations may be tacit (who to contact in case of problems, in which cases is it considered appropriate to contact someone etc) and may not necessarily be accommodated for in the estimation of required training periods. In addition to undertaking work in a prespecified way to keep variability low, the lean production worker may also be engaged in the role as informant: He may be expected to signal process inefficiencies and share information on improvement opportunities. This additional role is not strictly necessary to the operation of a lean production setup but it may be applied as a means for reducing variability. 
The TMS inspired theory of production accommodates for a quite different role for the worker. In this philosophy, the skills and knowledge of the worker is not only related to the role as producer and the worker's role in process improvement is not restricted to that of informant. Instead, she may be considered the co-designer of practices that simultaneously create lean processes and facilitate further experimentation and learning. In this process, she is also a learner as she improves her skills for undertaking this role and paradoxically also reduces the need for these skills in the specific production activity as it is gradually being stabilized and codified. Within Toyota, this paradox is resolved through the promise of a more transient role for the employee as indicated in several writings on TPS HRM practices. E.g. workers may be promised - if not life term employment then at least corporate commitment to long term employment [16], the most competent workers may be deliberately idled and eventually moved to other activities requiring improvement work [13] and team leader positions may be filled from within [17]. Such transient role also works to offset the larger investments in skill development as does the more general nature of these skills compared to the process specific skills emphasized under the transformation perspective.

This proposal for a TMS inspired theory of production may be applied in the attempt to discriminate between practices that are modeled over such theory-in-use versus practices that are modeled over alternative theories of production. Thereby research on TMS inspired organizational transformation may be improved. Presently this research suffer a severe limitation as only an isomorphic adoption of either lean practice or discourse are considered real exemplars of Toyota inspired transformation [18].

\section{Conclusions}

The paper suggests viewing managerial concepts as the content of organizational transformation, which then becomes a matter of adapting practices to match these concepts rather than that of adopting practices and discourse found in literature. Through the notion of "theories of production" a framework that encompasses and highlights differences between an industrial engineering perspective on Toyota (lean) and organizational theorists' perspectives on Toyota management system is developed. The paper contributes with a theory of production within TMS that is contrasted to both a traditional Western theory of production as well as an industrial engineering theory of Japanese production known as lean production. This proposed theory of production within TMS conceptualizes production as a unique arena for learning and thereby points out a bidirectional link between production and wider organization.

\section{References}

1. Hines, P., Holwe, M., Rich, N.: Learning to evolve - A review of contemporary lean thinking. International Journal of Operations \& Production Management 24, 994-1011 (2004)

2. Liker, J.K., Fruin, W.M., Adler, P.S.: Bringing Japanese Management Systems to the United States. In: Liker, J.K., Fruin, W.M., Adler, P.S. (eds.) Remade in America; Transplanting and Transforming Japanese Management Systems, Oxford University Press, New York (1999) 
3. Shah, R., Ward, P.T.: Lean manufacturing: context, practice bundles, and performance. Journal of Operations Management 21, 129-149 (2003)

4. Chan, J.S., Samson, D.A., Sohal, A.S.: An Integrative Model of Japanese Manufacturing Techniques. International Journal of Operations \& Production Management 10, 37-56 (1990)

5. de Treville, S., Antonakis, J.: Could lean production job design be intrinsically motivating? Contextual, configurational, and levels-of-analysis issues. Journal of Operations Management 24, 99-123 (2006)

6. Lozeau, D., Langley, A., Denis, J.-L.: The corruption of managerial techniques by organizations. Human Relations 55, 537-564 (2002)

7. Spencer, B.: Models of organization and total quality management: A comparison and critical evaluation. The Academy of Management Review 19, 446-471 (1994)

8. Gustavsen, B., Hofmaier, B., Wikman, A., Philips, M.E.: Concept-driven Development and the Organization of the Process of Change: An Evaluation of the Swedish Work Life Fund. John Benjamins Publishing Company (1996)

9. Røvik, K.A.: Trender og translasjoner: ideer som former det 21. århundrets organisasjon. Universitetsforlaget, Oslo (2007)

10. Spear, S.J.: Just-in-Time in practice at Toyota: Rules-in-Use for building selfdiagnostic, adaptive work-systems. Working paper 02-043, Harvard Business School (2002)

11. Koskela, L.: An exploration towards a production theory and its application to construction. Doctoral dissertation, Helsinki University of Technology (2000)

12. Hopp, W.J., Spearman, M.L.: Factory Physics: Foundations of Manufacturing Management. McGraw-Hill, New York (2000)

13. de Treville, S.: Disruption, learning, and system improvement in just-in-time manufacturing. Doctoral dissertation, Harvard University (1987)

14. Spear, S., Bowen, H.K.: Decoding the DNA of the Toyota Production System. Harvard Business Review 77, 97-106 (1999)

15. Spear, S.J.: The High Velocity Edge, How market leaders leverage operational excellence to beat the competition. McGraw-Hill, New York (2009)

16. Pil, F.K., MacDuffie, J.P.: Transferring Competitive Advantage Across Borders. A Study of Japanese Auto Transplants in North America. In: Liker, J.K., Fruin, W.M., Adler, P.S. (eds.) Remade in America; Transplanting and Transforming Japanese Management Systems, Oxford University Press, New York (1999)

17. Adler, P.S.: Hybridization, Human Resource Management at Two Toyota Transplants. Ibid

18. Pettersen, J.: Translating Lean Production, From Managerial Discourse to Organizational Practice. Doctoral dissertantion, Linköping University (2009) 